\title{
Delegates face many challenges negotiating Biosafety Protocol
}

In mid-February, delegates from many of the 183 nations in the UN system will meet in Cartagena, Colombia, for the sixth and supposedly final time to review and complete a document known as the Biosafety Protocol. Part of the Convention on Biological Diversity (CBD), the Biosafety Protocol was conceived as an instrument for preserving biological diversity against potential adverse effects from living genetically modified organisms. Critics of the draft document say that certain broader provisions, if implemented, could severely disrupt international trade involving a wide array of products derived from modern biotechnology.

The UN treaty establishing the CBD was framed in mid-1992, following a UN conference held in Rio de Janeiro, and the convention came into force soon thereafter. Since then, at least 172 countries have ratified the treaty, including a mixture of fully industrialized and developing nations, including the UK, France, Japan, and most African countries.

Although US President Clinton signed the CBD in 1993, the US Senate has not ratified the treaty, making US participation in Biosafety Protocol-related negotiations potentially awkward. Nonetheless, according to US officials, despite having "somewhat less leverage" from not formally being a party to the convention, the members of the US delegation generally expect to "participate on an equal basis" in Colombia with representatives from nations that have ratified CBD, according to officials.

Although the draft Biosafety Protocol focuses on "the risks from living modified organisms (LMOs) resulting from modern biotechnology," the scope and several provisions appear to reach beyond LMOs to include a wide range of products that derive from such organisms. Thus, some observers point out, the protocol may pertain not only to all genetically modified microorganisms, plants, and animals, but also to seeds, pharmaceutical products, agricultural commodities, and even finished goods, such as processed foods, cloth and clothing, or other materials that are fashioned some way or include ingredients from LMOs.

The draft protocol contains a wide range of provisions describing how and to what matters it is to be applied. For instance, the draft includes notification and liability pro- visions. In some versions, those provisions appear to call for an exchange of formal notices and acknowledgments between import and export countries for virtually each and every shipment involving LMOs.

Meanwhile, other provisions outline a system for assigning liability as well as steps for dealing with damage to biological diversity caused by the movement of LMOs across national boundaries. Further provisions describe risk assessments that incorporate criteria based on "social, economic, cultural, ethical, agricultural, and animal health considerations."

In addition, the document calls for sharing of information on LMOs and their potential risks, for industrialized nations to engage in "capacity building" by helping developing nations "enhance technological and institutional capacities through training in science," and for trade restrictions to be imposed under certain circumstances. This includes imposing restrictions on countries that do not subscribe to the protocol.

Although US officials say they are "very concerned about protecting the global environment and biodiversity," they also see many of these proposals as problematic. "We don't want an unrealistic, overburdensome system that would snarl world trade in food, agriculture, and pharmaceuticals." For instance, a central US position is that only those LMOs with a robust effect on biodiversity should be covered by the proposals, according to one member of the delegation. But nonliving products derived from LMOs "absolutely should not be."

However, other national delegations, notably those from several African countries and other developing nations, have consistently argued that LMO-derived products "somehow could affect biodiversity or health" and thus should be covered under the protocol. Although several European representatives have seemed willing to exempt pharmaceutical products from consideration, they appear not to have extended that willingness to agricultural commodities.

This stance may reflect a continuing difference between US and European officials over whether food or other products derived from genetically modified plants should be labeled. "The US position is that there is no reason to label a product merely because of the way it was produced, unless there is a specific health risk," an official says.

In general, US officials have broad backing from industry and have heard little opposition from environmental organizations on these positions. However, a coalition of public interest groups, including the Institute for Agriculture and Trade Policy (Minneapolis, MN) and the Community Nutrition Institute (Washington, DC), argue that labeling "is an appropriate issue" for consideration in Colombia, and that delegates have the right to "decide the level of risk they will accept," and that a "rigorous protocol. . .is absolutely necessary to protect the safety of humankind and the environment."

Meanwhile, a broad coalition of 24 industry groups, including the Biotechnology Industry Organization (BIO; Washington, DC), the Grocery Manufacturers of America (GMA; Washington, DC), the American Crop Protection Association (Washington, DC), and the National Restaurant Association (Washington, DC), recently urged President Clinton-through letters sent to the White House and in meetings with state department officials-to take up their concerns over the Biosafety Protocol and its potential adverse impact on biotechnology-derived products. "The current draft contains non-tariff trade barriers. . .and would be a significant new impediment to trade," points out Mary Saphos, GMA senior vice president for government affairs.

In addition to this industrial coalition, representatives from individual biotechnology companies also are calling for substantial changes in the draft Biosafety Protocol. "I would like to see a reasonable, fair, effective, and workable protocol," says Bob Harness, director of government affairs in Washington for Monsanto (St. Louis, MO). "There is an emerging feeling that if a reasonable protocol can be negotiated, the US should ratify it. But the scope of the [draft] and extent of its provisions are problematic."

The current proposals "look grim," says Val Giddings of BIO. "I would like to see this misbegotten exercise abandoned. . .unless the delegates limit the scope and focus [to] the subset of LMOs that could really affect biodiversity." He suggests that it may require high-level negotiations between heads of state before these matters are set straight.

Jeffrey L. Fox 